\title{
Alternative Petlyuk Distillation Configurations for the Separation of Four-Component Mixtures
}

\author{
Massimiliano Errico, ${ }^{* \dagger}$ Pietro Pirellas, ${ }^{\dagger}$ Ben-Guang Rong, ${ }^{*} \neq$ and Juan Gabriel Segovia-Hernandez ${ }^{\S}$ \\ ${ }^{\dagger}$ Università degli Studi di Cagliari, Dipartimento di Ingegneria Meccanica, Chimica e dei Materiali, Via Marengo 2, 09123 Cagliari, \\ Italy \\ ${ }^{\ddagger}$ University of Southern Denmark, Department of Chemical Engineering, Biotechnology and Environmental Technology, Niels Bohrs \\ Allé 1, DK-5230 Odense M, Denmark \\ ${ }^{\S}$ Universidad de Guanajuato, Departamento de Ingeniería Química, Campus Guanajuato, Noria Alta s/n, 36050, Guanajuato, Gto. \\ México
}

ABSTRACT: The Petlyuk configuration represents an attractive alternative to the simple distillation column sequences because of its potential in energy saving. This point was extensively discussed for three-component mixtures. Moving to quaternary mixtures the complexity of the Petlyuk configuration represents the main barrier of its possible implementation in the industrial practice. In the present work, a set of new alternative distillation configurations to the four-component Petlyuk is presented. A hydrocarbon and an alcohol mixture are considered to prove their applicability. The total annual cost, together with the thermodynamic efficiency and the carbon dioxide emissions, are considered as comparison index between the Petlyuk and the alternative configurations. The results obtained proved that for the cases considered at least one of the alternative configurations showed a better or at least the same performance of the Petlyuk arrangement. For this reason, the new configurations are worth of consideration when four-component mixtures are considered.

\section{INTRODUCTION}

Distillation and energy saving are two topics interconnected by the necessity to reduce the operative costs of distillation units increasing, at the same time, the profitability of the plant. For this reason, research and industrial experience are more than ever focused in finding new and feasible configurations to reduce the production's energy demand. Many research works have been focused on the screening of distillation alternatives from the point of view of energy and economics. Lucia and McCallum ${ }^{1}$ proposed an approach based on the stripping line distant function, Halvorsen and Skogestad ${ }^{2}$ reviewed different distillation schemes using the Vmin diagram to determine the overall minimum energy requirement, and Kiss et al. $^{3}$ proposed a scheme that by means of different selection criteria helps the designer in the choice of the most appropriate distillation technology. More recently, Luyben ${ }^{4}$ quantitatively explored how the value of the products and the difficulty of the separation affects the design of the chemical processes.

Two milestones are recognized by the research community as meaningful improvements in separations performed by distillation. The former is the introduction of structures with a partition wall inside the shell and the latter can be considered the definition of the Petlyuk configuration. 5,6 Both of them were introduced almost 50 years ago but only recently have been successfully applied into the industrial practice for a limited number of feed components. Considering threecomponent separations, the Petlyuk arrangement is composed by a prefractionator connected by two thermal couplings to the main column where the three products are obtained. If the prefractionator is included in the main column, the corresponding divided wall column (DWC) configuration is obtained. The two alternatives are reported, respectively, in
Figure $1 \mathrm{a}$ and $\mathrm{b}$. In both cases, only one condenser and one reboiler are employed. It was clearly demonstrated that for a

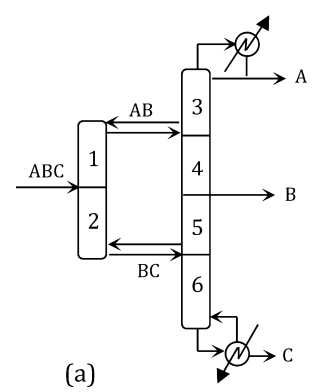

(b)

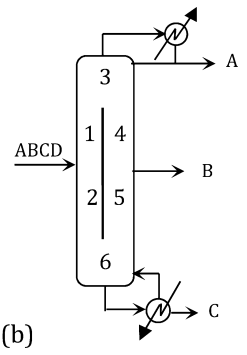

Figure 1. Three-component Petlyuk scheme (a) and the correspondent DWC (b).

three-component mixture, the Petlyuk configuration can save up to $30 \%$ of the energy consumption compared to the classical separation sequences. ${ }^{7-10}$ Despite this evidence, at least three valid hurdles contributed in the late development of Petlyuk and DWC configurations in the industrial practice. The first is the absence of recognized design methods, the second is the complexity of the structure, and the third reason is the difficult in the process control. The research efforts, focused around these three points, contributed to reach more than one hundred operative DWCs around the world for ternary distillation. ${ }^{11}$

Received: December 15, 2014

Revised: March 28, 2015

Accepted: April 7, 2015

Published: April 7, 2015 
Regarding the first point, different design methods have been proposed. Among all, Carlberg and Westerberg ${ }^{12}$ extended the Underwood's equations for the Petlyuk configuration, Triantafyllou and Smith $^{13}$ decomposed the Petlyuk configurations into three simple columns where the prefractionator column is equipped with a partial condenser and a partial reboiler. Ramirez-Corona et al. ${ }^{14}$ used a shortcut design model to describe the system as nonlinear programming problem. Guterrez-Antonio et al. ${ }^{15}$ used a multiobjective genetic algorithm to minimize both the heat duty and the number of stages considering the constraints in the product purity. More recently, Chen et al. ${ }^{16}$ introduced the overdesign as a method to extent the process flexibility and operability.

The second hurdles about the complexity of the structure is derived from the opposite transfer of one vapor stream between the top of the prefractionator and the main column and between the bottom of the main column and the prefractionator. Agrawal ${ }^{17}$ proposed a set of more operable configurations where the condenser and the reboiler are placed on different columns. The same author introduced also alternative configurations where the two-way thermal coupling is substituted by a one-way liquid stream through adding the additional column section. ${ }^{18}$ Rong and Turunen ${ }^{19}$ presented a new generalized method to produce all the thermodynamically equivalent configurations for Petlyuk and any other thermally coupled configurations. Thermodynamically equivalent configurations are more operable in terms of vapor transfer between the columns compared to the Petlyuk arrangement.

Finally, the control issue was extensively discussed in the literature, ${ }^{20}$ pointing out that without a proper control strategy, it is not possible to achieve the potential energy savings. ${ }^{21}$ Different approaches were proposed, from the use of proportional-integral controller ${ }^{22}$ to the implementation of model predictive control. ${ }^{23}$ Anyway, as summarized in the review of Kiss and Bildea, ${ }^{24}$ the DWC has good controllability properties. It is possible to assert that for the case of three component separations, the Petlyuk and its equivalent DWC configuration has the potential of a noteworthy energy saving; different design methods are available, structure complexities are overcome by using the thermodynamically equivalent configurations and moreover the control issues are solved. It is clear that the same results are aimed for different number of feed components. Moving from three to four components, the complexity of the Petlyuk and DWC structure increases, and up till now, only a few studies are focused on the possible applications of these configurations. ${ }^{25,26}$ The aim of the present study is to propose alternative configurations to the Petlyuk/ DWC arrangement for a four-component separation. The benefit of the alternatives proposed is a simple design with a less or comparable total annual cost compared to the corresponding Petlyuk configuration. Two different case studies are presented to support the new sequences.

\section{SYNTHESIS PROCEDURE}

The synthesis procedure is a systematic methodology that allows the prediction of all the alternatives generable from a configuration chosen as a reference. For a four or more component mixture Rong and Turunen ${ }^{27}$ reported a method to generate the heat-integrated thermally coupled alternatives for the Petlyuk configuration starting from the unique nonsharp sequence which has the same number of $N-1$ columns for an $\mathrm{N}$-component mixture. Now, with the new synthesis procedure reported in Rong et al. ${ }^{28}$ and Rong, ${ }^{29}$ new alternatives with less than $N-1$ columns for Petlyuk configuration can be generated for an $\mathrm{N}$-component mixture. The objective of this work is to generate the new alternatives for quaternary distillations. For a four-component mixture, the nonsharp configuration reported in Figure 2 is considered. In this six-column sequence, usually

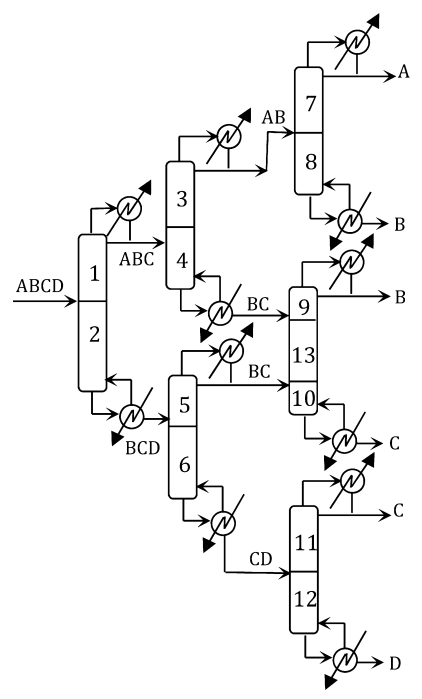

Figure 2. Fully sloppy configuration for a four-component feed.

referred as fully sloppy configuration, all the mixtures with three or more components are separated by symmetric sloppy splits. The corresponding Petlyuk configuration can be obtained in two steps: in the first one the column sections where the same mixture or component is separated are merged. In the case considered, sections 4 and 5, 8 and 9, 10, and 11 are combined, reducing the number of column to three. Then, considering that in the Petlyuk configuration there is only one condenser and one reboiler independently from the number of component to be separated, all the condensers and reboilers associated with nonproduct streams can be substituted with a thermal coupling. The corresponding configuration is showed in Figure 3a. The quaternary DWC sequence is reported in Figure $3 \mathrm{~b}$. The Petlyuk configuration has three columns and five thermal couplings, the corresponding DWC has three vertical partitions implemented in the same shell. Both sequences are attractive for their potential in costs reduction but the complexity of the system makes impractical a real application. Intensified configurations alternative to the Petlyuk
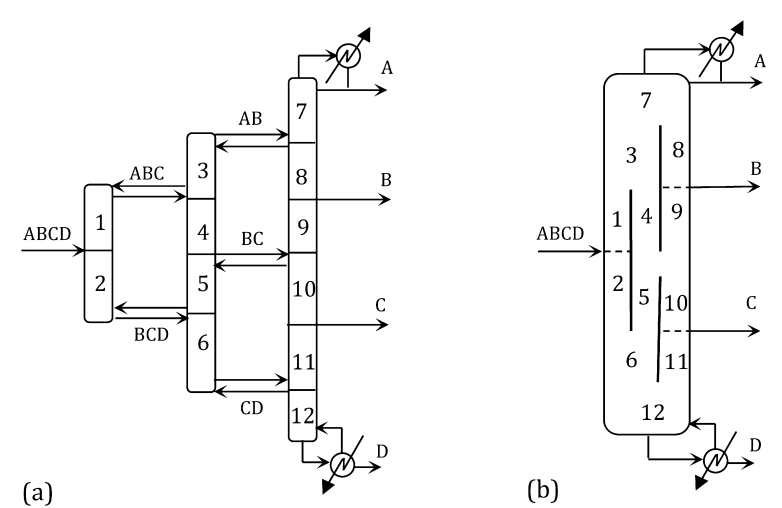

Figure 3. Four-component Petlyuk scheme (a) and the correspondent DWC (b). 


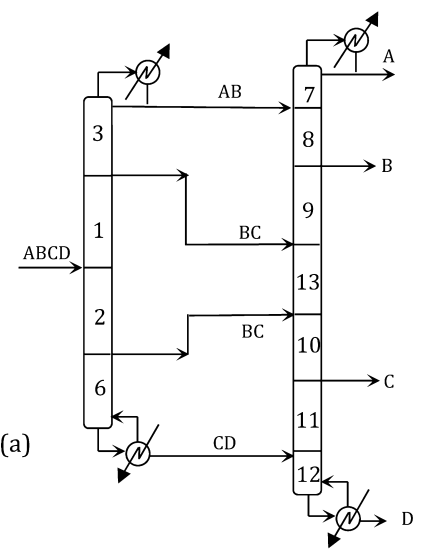

(b)

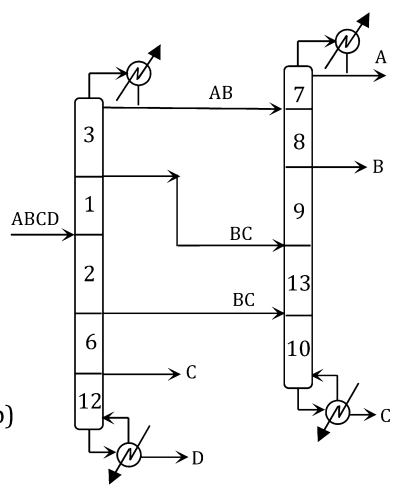

(c)

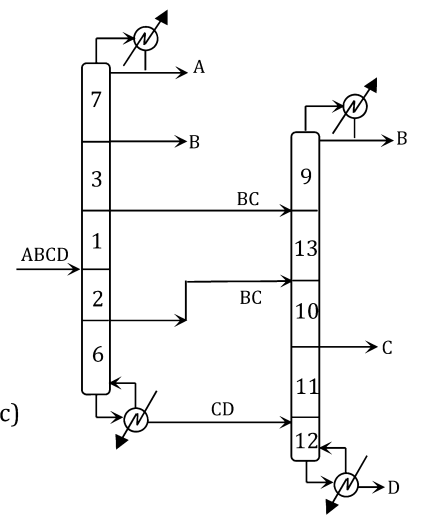

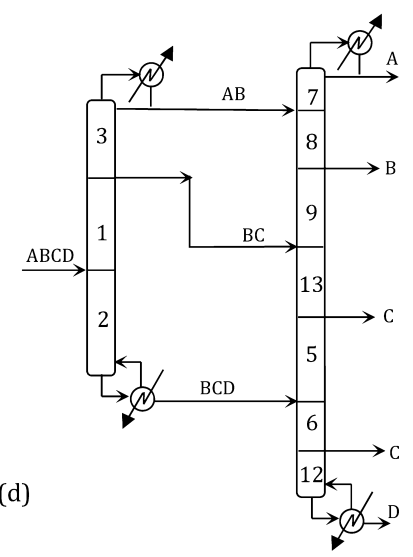

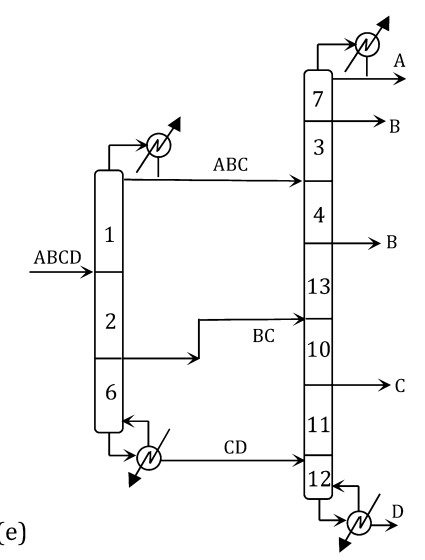

Figure 4. Alternative configurations.

arrangement can be obtained starting from the fully sloppy configuration of Figure 2 applying four different strategies:

1. Closed-heat-integration strategy to combine individual columns. This strategy is used to combine two columns by heat integration between a condenser and a reboiler coproducing a same product. This will reduce the number of columns.

2. Thermal coupling strategy to eliminate a condenser or a reboiler. This strategy is used to eliminate a condenser or a reboiler associated with a mixture of two or more components. This will reduce the number of heat exchangers.

3. Rearrangement of column sections strategy to generate thermodynamically equivalent structures. This strategy is used to recombine the column sections in a thermally coupled configuration through movement of the movable column sections. This will generate the thermodynamically equivalent structures, which have different columns than the original thermally coupled configuration.

4. Elimination of the single-section-side columns strategy to produce the intensified distillation systems. For a thermally coupled configuration, there are thermodynamically equivalent structures in which there are singlesection-side columns. This strategy is used to eliminate the single-section-side columns to generate the intensified distillation systems with fewer columns.

Applying the four point strategy presented, the five configurations reported in Figure 4 are obtained. In particular, the configuration reported in Figure 4a is obtained by applying the strategy 1 to merge section 8 with section 9 and section 10 with section 11, then following the strategy 2 the condenser associated with the submixture $\mathrm{ABC}$ and the reboiler associated with the submixture BCD are substituted by thermal couplings. Strategy 3 is used to rearrange section 3 above section 1 and section 6 below section 2; finally, single sections 4 and 5 are eliminated, as indicated in the strategy 4. Similarly the configurations reported in Figure $4 b-e$ are obtained. Analyzing all the configurations generated is possible to notice that are all composed by two columns, moreover in sequences $4 \mathrm{~b}$ and $4 \mathrm{~d}$, the stream $C$ is obtained twice, in sequences $4 c$ and $4 \mathrm{e}$ the component $\mathrm{B}$ is recovered in two separate streams. Only to the sequence $4 \mathrm{a}$ is associated the minimum number of streams.

As reported before, in the Petlyuk scheme, independent of the number of components separated, only one condenser and one reboiler are employed. The configuration of Figure 4a can reach this target when the condenser and the reboiler associated with the submixtures $A B$ and $C D$, respectively, are substituted by a thermal coupling. The resulting alternative is reported in Figure 5.

The synthesis procedure has been summarized in Figure 6. The eight-step flowchart reports the general methodology based on the four strategies described before.

\section{CASE STUDY AND COMPARISON INDEXES}

To test the applicability of the new intensified configurations, two case studies have been considered. The first mixture is a four-component $n$-paraffin feed. The composition and the product purity targets are shown in Table 1 . The second case 


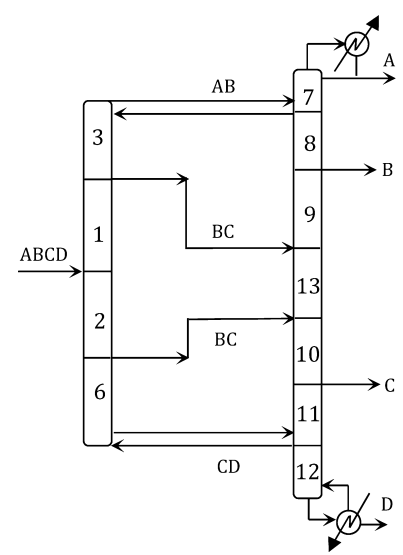

Figure 5. Thermally coupled alternative configuration.

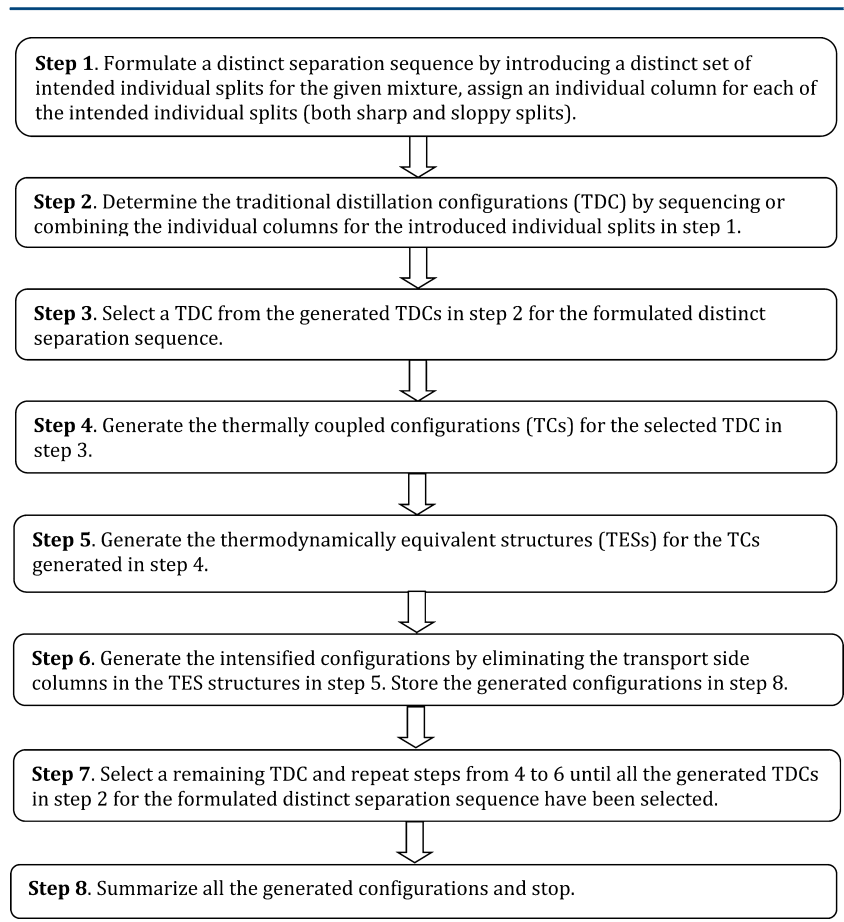

Figure 6. Generalized procedure for the synthesis of the alternative intensified configurations.

Table 1. Feed Composition and Purity Target for Case Study 1

\begin{tabular}{cccc} 
& component & feed composition [mol frac.] & purity target [mol frac.] \\
A & butane & 0.05 & 0.990 \\
B & hexane & 0.10 & 0.970 \\
C & heptane & 0.10 & 0.974 \\
D & nonane & 0.75 & 0.997 \\
\hline
\end{tabular}

considered is a mixture of alcohols with the composition and purity targets specified in Table 2 . For both cases, a saturated liquid feed flow rate of $100 \mathrm{kmol} \mathrm{h}^{-1}$ is considered.

Three different indexes were selected for the configurations comparison: the total annual cost, the thermodynamic efficiency, and the carbon dioxide emission. The total annual cost (TAC) is obtained as a sum of the operative and the annualized capital costs as reported in eq 1 .
Table 2. Feed Composition and Purity Target for Case Study 2

\begin{tabular}{|c|c|c|c|}
\hline & component & feed composition [mol frac.] & purity target [mol frac.] \\
\hline A & methanol & 0.05 & 0.990 \\
\hline B & ethanol & 0.10 & 0.990 \\
\hline $\mathrm{C}$ & 1-heptanol & 0.10 & 0.990 \\
\hline $\mathrm{D}$ & 1-decanol & 0.75 & 0.990 \\
\hline
\end{tabular}

The operative costs were evaluated taking into account the cost of the water and the vapor in the condenser and reboiler, respectively. The costs of the auxiliary fluids were obtained from Rev et al. ${ }^{30}$ The capital costs were considered as the sum of the costs of the condensers, reboilers, column shell, and trays, evaluated according to the Guthrie's method. ${ }^{31}$ A mean investment time of 10 years was used to annualize the capital costs. The second index considered is how efficient the energy is being used. This information is expressed by the thermodynamic efficiency $(\eta)$ evaluated as reported by Seader et $\mathrm{al}^{32}$ and defined in eq 2

$$
\eta=-\frac{W_{\min }}{\left(-L W-W_{\min }\right)}
$$

where $W_{\min }\left[\mathrm{kJ} \mathrm{h}^{-1}\right]$ is the minimum work of separation and $\mathrm{LW}\left[\mathrm{kJ} \mathrm{h}^{-1}\right]$ the lost work. All the thermodynamic properties for the thermodynamic efficiency evaluation were obtained through the process simulator Aspen PlusV8.0 for the input and output streams. The last index used to compare the different configurations is the carbon dioxide emission $\left(m_{\mathrm{CO}_{2}}\right)$ because, as a greenhouse gas, it is directly related to the global warming. The amount of carbon dioxide emitted was evaluated by eq 3 following the method reported by Gadalla et al. ${ }^{33}$

$$
m_{\mathrm{CO}_{2}}=\left(\frac{Q_{\mathrm{FUEL}}}{\mathrm{NHV}}\right)\left(\frac{\% C}{100}\right) \alpha
$$

where $Q_{\text {fuel }}\left[\mathrm{kJ} \mathrm{h}^{-1}\right]$ is the heat generated by the combustion reaction, NHV $\left[\mathrm{kJ} \mathrm{kg}^{-1}\right]$ is the net heating value of a fuel with a carbon content of $\% \mathrm{C}$, and $\alpha$ the ratio of molar masses of $\mathrm{CO}_{2}$.

\section{SIMULATION AND DESIGN}

All the configurations were simulated by means of Aspen Plus V8.0. The NRTL thermodynamic method was used and sieve trays columns were considered. The column pressure was optimized for each column considering the possibility to use water in the condenser. The minimum temperature for the columns overhead vapor was defined to $323 \mathrm{~K}$.

In order to get the design parameters of all the alternative sequences, the fully sloppy configuration of Figure 2 was first simulated using the short-cut method of Underwood-Gilliland-Winn already implemented in Aspen Plus. The parameters obtained were used to initialize the stage-to-stage rigorous method RadFrac. The number of stages, feed locations, and reflux ratios were then optimized for the minimum energy consumption. The sensitivity tool was used to define the optimal design and the total reboiler duty was defined as objective function. The results obtained are reported in Tables 3 and 4 for the hydrocarbon and alcohol feed, respectively. 
Table 3. Case Study 1: Fully Sloppy Configuration's Design Parameters and Energy Consumption

\begin{tabular}{lllllll} 
& $C_{1}$ & $C_{2}$ & $C_{3}$ & $C_{4}$ & $C_{5}$ & $C_{6}$ \\
number of stages & 16 & 27 & 14 & 25 & 33 & 19 \\
reflux ratio & 0.90 & 0.56 & 4.60 & 0.44 & 2.50 & 12.70 \\
feed location & 9 & 23 & 7 & 17 & 13 & 12 \\
pressure [bar] & 2 & 2.5 & 1 & 5 & 1 & 1 \\
distillate [kmol/h] & 14.0 & 11.5 & 8.5 & 4.8 & 3.5 & 2.0 \\
diameter [m] & 0.67 & 0.35 & 0.66 & 0.20 & 0.31 & 0.58 \\
condenser duty [kW] & 238 & 149 & 434 & 37 & 99 & 248 \\
reboiler duty [kW] & 541 & 162 & 247 & 70 & 95 & 260 \\
\hline
\end{tabular}

Table 4. Case Study 2: Fully Sloppy Configuration's Design Parameters and Energy Consumption

\begin{tabular}{lllllll} 
& $C_{1}$ & $C_{2}$ & $C_{3}$ & $C_{4}$ & $C_{5}$ & $C_{6}$ \\
number of stages & 41 & 49 & 16 & 38 & 26 & 18 \\
reflux ratio & 0.14 & 0.17 & 1.98 & 0.13 & 1.80 & 10.80 \\
feed location & 21 & 40 & 9 & 23 & 12 & 12 \\
pressure [bar] & 1 & 1 & 1 & 1 & 1 & 1 \\
distillate [kmol/h] & 25.0 & 20.0 & 12.0 & 10.0 & 5.0 & 3.0 \\
diameter [m] & 0.94 & 0.49 & 0.73 & 0.31 & 0.38 & 0.72 \\
condenser duty [kW] & 412 & 321 & 479 & 111 & 171 & 472 \\
reboiler duty [kW] & 1203 & 342 & 575 & 165 & 179 & 499 \\
\hline
\end{tabular}

4.1. Petlyuk Configuration. The design of the Petlyuk configuration was performed using the sequential design method based on the correspondent among the column sections functionality. ${ }^{34,35}$ In this way, once the design of the fully sloppy configuration of Figure 2 was obtained, the configuration parameters were transposed to the analogous sections of the Petlyuk configuration. The thermal coupling the flow rates were defined as the minimum possible value to ensure the products purity targets. ${ }^{36}$ The results obtained, together with the comparison indexes, are summarized in Tables 5 for both case studies.

Table 5. Case Study 1 and 2: Petlyuk Configuration's Design Parameters and Comparison Indexes

\begin{tabular}{|c|c|c|c|c|c|c|}
\hline & \multicolumn{3}{|c|}{ case study 1} & \multicolumn{3}{|c|}{ case study 2} \\
\hline & $C_{1}$ & $C_{2}$ & $C_{3}$ & $C_{1}$ & $\mathrm{C}_{2}$ & $C_{3}$ \\
\hline number of stages & 16 & 41 & 77 & 41 & 65 & 82 \\
\hline reflux ratio & & & 27.05 & & & 14 \\
\hline feed location & 9 & 27 & 38 & 21 & 49 & 50 \\
\hline pressure $[\mathrm{bar}]$ & 2 & 2.5 & 5 & 1 & 1 & 1 \\
\hline distillate $[\mathrm{kmol} / \mathrm{h}]$ & 17.0 & 78.6 & 4.8 & 12.1 & 47.3 & 10 \\
\hline diameter $[\mathrm{m}]$ & 0.56 & 0.80 & 1.15 & 0.49 & 1.04 & 1.61 \\
\hline condenser duty $[\mathrm{kW}]$ & & & 731 & & & 1465 \\
\hline reboiler duty $[\mathrm{kW}]$ & & & 1506 & & & 2465 \\
\hline capital costs $[\mathrm{k} \$ / \mathrm{y}]$ & & 42.27 & & & 58.08 & \\
\hline $\mathrm{TAC}[\mathrm{k} \$ / \mathrm{y}]$ & & 433 & & & 702 & \\
\hline$\eta[\%]$ & & 47.0 & & & 37.8 & \\
\hline $\mathrm{CO}_{2}[\mathrm{~kg} / \mathrm{h}]$ & & 658 & & & 1077 & \\
\hline
\end{tabular}

4.2. Alternative Configurations. Following the same design methodology cited for the Petlyuk configuration, the alternative configurations reported in Figure 4 have been simulated using the correspondence of column sections functionality. The results for the composition case 1 and 2 are reported in Table 6 . It should be noted that only the results for the configuration of Figure $4 \mathrm{a}$ are included in the table
Table 6. Case Study 1 and 2: Design Parameters and Comparison Indexes of the Alternative Configuration Reported in Figure 4a

\begin{tabular}{|c|c|c|c|c|}
\hline & \multicolumn{2}{|c|}{ case study 1} & \multicolumn{2}{|c|}{ case study 2} \\
\hline & $C_{1}$ & $\overline{C_{2}}$ & $C_{1}$ & $\mathrm{C}_{2}$ \\
\hline number of stages & 46 & 77 & 88 & 82 \\
\hline reflux ratio & 3.9 & 6.2 & 0.7 & 4.25 \\
\hline feed location & 43 & $37 / 39$ & 61 & $53 / 55$ \\
\hline pressure $[\mathrm{bar}]$ & 2.5 & 5 & 1 & 1 \\
\hline distillate $[\mathrm{kmol} / \mathrm{h}]$ & 11.5 & 4.8 & 20 & 10 \\
\hline diameter $[\mathrm{m}]$ & 0.89 & 0.74 & 1.03 & 0.83 \\
\hline condenser duty $[\mathrm{kW}]$ & 468 & 186 & 468 & 513 \\
\hline reboiler duty $[\mathrm{kW}]$ & 920 & 577 & 1310 & 669 \\
\hline capital costs $[\mathrm{k} \$ / \mathrm{y}]$ & \multicolumn{2}{|c|}{31.67} & \multicolumn{2}{|c|}{42.74} \\
\hline $\mathrm{TAC}[\mathrm{k} \$ / \mathrm{y}]$ & \multicolumn{2}{|c|}{430} & \multicolumn{2}{|c|}{572} \\
\hline$\eta[\%]$ & \multicolumn{2}{|c|}{51.7} & \multicolumn{2}{|c|}{46.9} \\
\hline $\mathrm{CO}_{2}[\mathrm{~kg} / \mathrm{h}]$ & \multicolumn{2}{|c|}{654} & \multicolumn{2}{|c|}{865} \\
\hline
\end{tabular}

because, for the composition cases considered, was the most convenient alternative from the energy consumption point of view. Among all the alternatives predicted, the one in Figure 4a, is the only configuration that performs the separation of the middle components once.

4.3. Thermally Coupled Alternative Configuration. The performances of the configuration reported in Figure 5 are here considered. This alternative represents the most close, regarding the structural design, to the Petlyuk configuration but with the extra benefit of a reduced number of thermal couplings and columns. The columns design was defined considering the corresponding parameters of the sequence of Figure $4 \mathrm{a}$. Because the main scope of the present work is to present configurations with a simplified design, the thermally coupled alternative was considered only for the case study 2 because the pressure distribution among the columns allows the natural flow of the vapor flow streams. The results obtained are summarized in Table 7.

Table 7. Case Study 2: Design Parameters and Comparison Indexes of the Thermally Coupled Alternative Configuration Reported in Figure 5

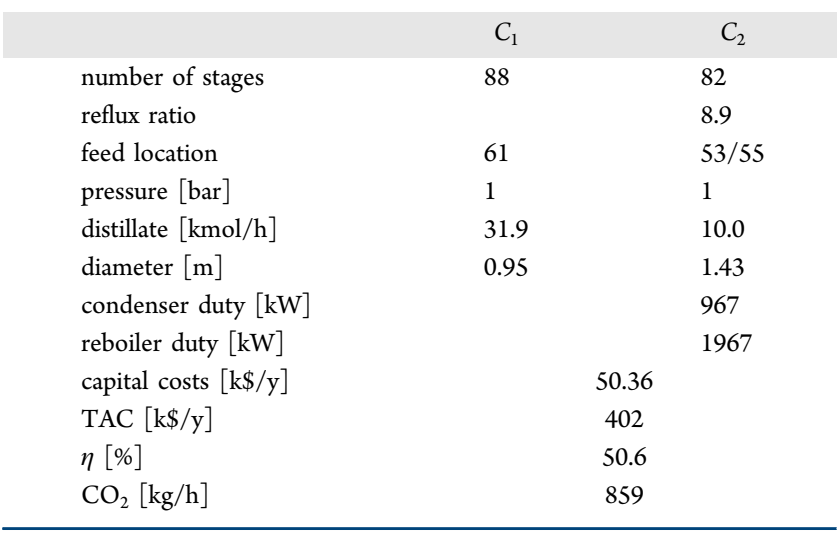

\section{RESULTS AND DISCUSSION}

In this section, the results obtained for the two feed cases are discussed and the Petlyuk configuration is compared with the alternative sequences based on the TAC, the thermodynamic efficiency, and the carbon dioxide emission. 
5.1. Case Study 1. The first feed case is a hydrocarbon mixture already reported in the literature. ${ }^{37}$ The comparison indexes for the Petlyuk and the alternative configuration are reported in Tables 5 and 6 , respectively.

5.1.1. TAC Comparison. It is possible to notice that, from an economic point of view, the Petlyuk and the alternative configuration showed almost the same value of the TAC. Regarding the capital costs, the intensified alternative reaches a $33.5 \%$ lower value due to the smaller exchanger area of the reboiler and condenser and the reduced number of column stages.

5.1.2. Thermodynamic Efficiency Comparison. The alternative configuration has $9 \%$ higher thermodynamic efficiency compared to the Petlyuk arrangement.

5.1.3. Carbon Dioxide Emission Comparison. As for the TAC value, there are not relevant differences in the amount of carbon dioxide emitted.

It is clear that in the case or equal or comparable indexes the simplest design of the configuration of Figure 4a represents the best alternative for the case considered. As discussed in Section 4.3 , the thermally coupled configuration of Figure 5 was not considered due to the disadvantageous pressure distribution.

5.2. Case Study 2. The second case study is the fouralcohol mixture. As for the previous case, the data are reported in Tables 5 and 6.

5.2.1. TAC Comparison. It is possible to notice that the alternative configuration realizes a $18.5 \%$ reduction of the TAC compare to the Petlyuk arrangement. Moreover 35.9\% savings in the capital costs are also observed.

5.2.2. Thermodynamic Efficiency Comparison. For the alternative configuration, the thermodynamic efficiency is 24.1\% higher than the Petluyk arrangement.

5.2.3. Carbon Dioxide Emission Comparison. For this case study, the alternative configuration realizes a $19.7 \%$ saving in the carbon dioxide emission.

If the results for the thermally coupled alternative reported in Table 7 are considered, an impressive $42.7 \%$ saving in the TAC is realized together with $20.2 \%$ saving in carbon dioxide emission. Also, in this case, the thermodynamic efficiency is $33.9 \%$ higher than the corresponding Petlyuk configuration. This case represents an evidence that for some composition cases the alternative configurations proposed could be able to outperform the Petlyuk scheme and for this reason could represent the preferred choice.

\section{CONCLUSIONS}

The three-component Petlyuk configuration has been always considered as one of the most interesting distillation options for the achievable savings in the energy consumption. The attempt to extend this result to four-component mixtures is considered with some kind of skepticism for the complex design. In the present work, a new set of alternative configurations are presented as alternatives to the four-component Petlyuk scheme. The alternatives are generated systematically from the fully sloppy distillation sequence by means of a four-step procedure that includes the combination of individual columns, the introduction of thermal couplings, the column recombination and the elimination of single column sections. Two case studies are reported to prove their potential in substitute the complex Petlyuk arrangement. Three indexes are used for the comparison: the TAC, the thermodynamic efficiency and the carbon dioxide emission. In the first case considered, the alternative configuration proposed reach the same indexes of the Petlyuk scheme, but when the simplicity of the design is considered, it represents a more attractive solution. In the second case, the alternative proposed outperform all the indexes of the Petlyuk arrangements, reaching in the best case a considerable $42.7 \%$ reduction in the TAC.

It is not possible to generalize these results to all the fourcomponent separation cases but is important to emphasize that the alternatives proposed have the potential to reach the same performances of the Petlyuk scheme. The designer has the freedom to define a complete searching space of alternatives including also combinations of simple and divided wall columns or configurations with thermally coupled configurations or thermodynamically equivalent structures; anyway, also, the new configurations proposed should be included in the research space when the optimal configuration is searched.

\section{AUTHOR INFORMATION}

\section{Corresponding Authors}

*Tel.: +39 070 6755079. Fax: +39 070 6755067. E-mail: massimiliano.errico@dimcm.unica.it (M. Errico).

*Tel.: +45 65507481. Fax: +45 65507354. E-mail: bgr@kbm. sdu.dk (B.-G. Rong).

\section{Notes}

The authors declare no competing financial interest.

\section{ACKNOWLEDGMENTS}

Gratefully acknowledges Sardinia Regional Government for the financial support (P.O.R. Sardegna F.S.E. Operational Programme of the Autonomous Region of Sardinia, European Social Fund 2007-2013-Axis IV Human Resources, Objective 1.3, Line of Activity 1.3.1 "Avviso di chiamata per il finanziamento di Assegni di Ricerca”)

\section{REFERENCES}

(1) Lucia, A.; McCallum, B. R. Energy targeting and minimum energy distillation column sequences. Comput. Chem. Eng. 2010, 34, 931-942.

(2) Halvorsen, I. J.; Skogestad, S. Energy efficient distillation. J. Nat. Gas Sci. Eng. 2011, 3, 571-580.

(3) Kiss, A. A.; Flores Landaeta, S. J.; Infante Ferreira, C. A. Towards energy efficient distillation technologies-Making the right choice. Energy 2012, 47, 531-542.

(4) Luyben, W. L. Optimum product recovery in chemical process design. Ind. Eng. Chem. Res. 2014, 53, 16044-16050.

(5) Wright, R. O. U.S. Patent No. 2,471,134, May 24, 1949.

(6) Petlyuk, F. B.; Platonov, V. M.; Slavinskii, D. M. Thermodynamically optimal method for separating multicomponent mixtures. Int. Chem. Eng. 1965, 5, 555-561.

(7) Petlyuk, F. B. Distillation Theory and its Application to Optimal Design of Separation Units; Cambridge University Press: New York, 2004.

(8) Halvorsen, I. J.; Skogestad, S. Minimum energy consumption in multicomponent distillation. 2. Three-product Petlyuk arrangements. Ind. Eng. Chem. Res. 2003, 42, 596-604.

(9) Bruggemann, S.; Marquardt, W. Rapid screening of design alternatives for nonideal multiproduct distillation processes. Comput. Chem. Eng. 2004, 24, 165-179.

(10) Smith, R. Thermally-Coupled Columns: Distillation. Encyclopedia of Separation Science; Academic Press: London, 2000, 4363-4371; Vol. 9.

(11) Olujic, Z.; Jodecke, M.; Shilkin, A.; Schuch, G.; Kaibel, B. Equipment improvement trends in distillation. Chem. Eng. Proc.: Proc. Intensif. 2009, 48, 1089-1104. 
(12) Carlberg, N. A.; Westerberg, A. W. Temperature-heat diagrams for complex columns. 3. Underwood's method for the Petlyuk configuration. Ind. Eng. Chem. Res. 1989, 28, 1386-1397.

(13) Triantafyllou, C.; Smith, R. The design and optimization of fully thermally coupled distillation columns. Trans. IChemE, Part A 1992, $70,118-132$.

(14) Ramirez-Corona, N.; Jimenez-Gutierrez, A.; Castro-Aguero, A.; Rico-Ramirez, V. Optimum design of Petlyuk and divided-wall distillation systems using a shortcut model. Chem. Eng. Res. Des. 2010, 88, 1405-1418.

(15) Guterrez-Antonio, C.; Briones-Ramirez, A.; Jimenez-Gutierrez, A. Optimization of Petlyuk sequences using a multiobjective genetic algorithm with constraints. Comput. Chem. Eng. 2011, 35, 236-244.

(16) Chen, W.; Huang, K.; Chen, H.; Xia, C.; Wu, G.; Wang, K. Design and operation of dividing-wall distillation columns. 1. Diminishing the black-hole problem through over-design. Chem. Eng. Proc.: Proc. Intensif. 2014, 75, 90-109.

(17) Agrawal, R. More operable fully thermally coupled distillation columns configurations for multicomponent distillation. Chem. Eng. Res. Des. 1999, 77, 543-553.

(18) Agrawal, R. Thermally coupled distillation with reduced number of intercolumn vapor transfers. AIChE J. 2000, 46, 2198-2210.

(19) Rong, B.-G.; Turunen, I. A new method for synthesis of thermodynamically equivalent structures for Petlyuk arrangements. Trans. IChemE, Part A 2006, 84, 1095-1116.

(20) Kiss, A. A. Advanced Distillation Technologies. Design, Control and Applications; John Wiley and Sons Ltd: Chichester, U. K., 2013; Ch. 4 and 5 .

(21) Halvorsen, I. J.; Skogestad, S. Optiumal operation of Petlyuk distillation: steady-state behavior. J. Proc. Control 1999, 9, 407-424.

(22) Segovia Hernández, J. G.; Hernández, S.; Femat, R.; Jiménez, A. Control of thermally coupled distillation sequences with dynamic estimation of load disturbances. Ind. Eng. Chem. Res. 2007, 46, 546558.

(23) Rewagad, R. R.; Kiss, A. A. Dynamic optimization of a dividingwall column using model predictive control. Chem. Eng. Sci. 2012, 68, $132-142$.

(24) Kiss, A. A.; Bildea, C. S. A control perspective on process intensification in dividing-wall columns. Chem. Eng. Proc.: Proc. Intensif. 2011, 50, 281-292.

(25) Dejanovic, I.; Matijasevic, Lj.; Halvorsen, I. L.; Skogestad, S.; Jansen, H.; Kaibel, B.; Olujic, Z. Designing four-product dividing wall columns for separations of a multicomponent aromatics mixtures. Chem. Eng. Res. Des. 2011, 89, 1155-1167.

(26) Dejanovic, I.; Halvorsen, I. J.; Skogestad, S.; Jansen, H.; Olujic, Z. Hydraulic design technical challenges and comparison of alternative configurations of a four-product dividing wall column. Chem. Eng. Proc.: Proc. Intensif. 2014, 84, 71-81.

(27) Rong, B. G.; Turunen, I. New heat-integrated distillation configurations for Petlyuk arrangements. Chem. Eng. Res. Des. 2006, 84, 1117-1133.

(28) Rong, B. G.; Errico, M.; Segovia-Hernandez, J. G. New intensified distillation systems for quaternary Petlyuk configurations. Eur. Symp. Comput. Aided Proc. Eng. 2014, 97-102.

(29) Rong, B. G. A systematic procedure for synthesis of intensified nonsharp distillation systems with fewer columns. Chem. Eng. Res. Des. 2014, 92, 1955-1968.

(30) Rev, E.; Emtir, M.; Szitkai, Z.; Mizsey, P.; Fonyo, Z. Energy Savings of Integrated and Coupled Distillation. Systems. Comput. Chem. Eng. 2001, 23, S89-S92.

(31) Turton, R.; Bailie, R. C.; Whiting, W. B.; Shaeiwitz, J. A. Analysis, Synthesis and Design of Chemical Process, 2nd ed.; Prentice Hall: Upper Saddle River, NJ; 2004.

(32) Seader, J. D.; Henley, E. J.; Roper, D. K. Separation Process Principles, 3rd ed.; John Wiley \& Sons, Inc.: Chichester, U. K., 2013.

(33) Gadalla, M. A.; Olujic, Z.; Jansen, P. J.; Jonson, M.; Smith, R. Reducing $\mathrm{CO}_{2}$ emissions and energy consumption of heat-integrated distillation systems. Environ. Sci. Technol. 2005, 39, 6860-6870.
(34) Errico, M.; Rong, B.-G.; Torres-Ortega, C. E.; SegoviaHernandez, J. G. The importance of the sequential synthesis methodology in the optimal distillation sequence design. Comput. Chem. Eng. 2014, 62, 1-9.

(35) Errico, M.; Pirellas, P.; Torres-Ortega, C. E.; Rong, B.-G.; Segovia-Hernandez, J. G. A combined method for the design and optimization of intensified distillation systems. Chem. Eng. Proc.: Proc. Intensif. 2014, 85, 69-76.

(36) Calzon-McConville, C. J.; Rosales-Zamora, Ma.B.; SegoviaHernandez, J. G.; Rico-Ramirez, V. Design and optimization of thermally coupled distillation schemes for the separation of multicomponent mixtures. Ind. Eng. Chem. Res. 2006, 45, 724-732.

(37) Errico, M.; Rong, B.-G. Modified simple column configurations for quaternary distillations. Comput. Chem. Eng. 2012, 36, 160-173. 